\title{
BREAST CANCER SCREENING IN A RESOURCE POOR COUNTRY: ULTRASOUND VERSUS MAMMOGRAPHY
}

\author{
Olubukola A.T Omidiji ${ }^{1}$, Princess C. Campbell ${ }^{2}$, Nicholas K. Irurhe ${ }^{1}$, Omolola M. Atalabi ${ }^{3}$ and Ol- \\ uyemisi O.Toyobo ${ }^{4}$ \\ Ghana Med J 2017; 51(1): 6-12～DOI: http://dx.doi.org/10.4314/gmj.v51i1.2
}

\begin{abstract}
${ }^{1}$ Department of Radiation Biology, Radiotherapy, Radiodiagnosis and Radiography, College of Medicine, University of Lagos, Lagos, Nigeria, ${ }^{2}$ Department of Community Medicine and Primary Care, College of Medicine University of Lagos, Nigeria, ${ }^{3}$ Department of Radiodiagnosis, College of Medicine University of Ibadan/University College Hospital, Ibadan. Oyo State Nigeria ${ }^{4}$ Department of Radiology, Olabisi Onabanjo University Teaching Hospital, Ogun State, Nigeria
\end{abstract}

Corresponding author: Dr. Olubukola A. T. Omidiji

E-mail: olubukolaomidiji@yahoo.com

Conflict of interest: None declared

\section{SUMMARY}

Background: Breast cancer is the commonest female cancer in Nigeria. Despite its increased awareness, affordability of available screening tools is a bane. Mammography, the goal standard for screening is costly and not widely available in terms of infrastructure, technical/personnel capabilities. Ultrasound is accessible and affordable.

Objectives: This study compared the use of ultrasound and mammography as breast cancer screening tools in women in South West Nigeria by characterizing and comparing the prevalent breast parenchyma, breast cancer features and the independent sensitivity of ultrasound and mammography.

Methods: This cross sectional comparative descriptive study used both ultrasound and mammography as screening tools in 300 consenting women aged 30 to 60 years who attended a free breast cancer screening campaign in a tertiary hospital in Lagos. Categorical variables were presented in tables and Chi squares for associations P- value set at \pm 0.1 .

Results: Mean age was $41.01+6.5$ years with majority in the $30-39$ year age group $139(55 \%)$. Fatty (BIRADS A and B) parenchyma predominated \{ultrasound 237 (79\%); mammography $233(77.7 \%)$ \} in all age groups. $7(2.3 \%)$ were confirmed malignant by histology with (6) in the 30-39 age group and (1) in the 40-49 age group. Ultrasound detected all the confirmed cases $7(100 \%)$, whereas mammography detected $6(85 \%)$. Sensitivity was higher using ultrasound (100\%) than mammography $(85.7 \%)$.

Conclusion: Ultrasound can be utilized as a first line of screening especially in remote/rural areas in developing world.

Funding: Part funding from Run for Cure governmental organization

Keywords: Breast Cancer, Women, Ultrasound, Mammography, Sensitivity

\section{INTRODUCTION}

Breast cancer is the leading female malignancy globally, and the most common female cancer in Nigeria. ${ }^{1}$ It accounts for three-fourths of total deaths from the disease worldwide. $^{2}$ Late presentation of patients at advanced stages when little or no benefit can be derived from any form of therapy has been the hallmark of breast cancer in Nigerian women, with survival rates less than $10 \%{ }^{2}$

Survival rates are much higher in the developed countries than in the developing countries with lower incidence rates, due to lack of early detection programmes with late presentation of the disease, inadequate diagnostic and treatment facilities in the developing countries. ${ }^{3}$ Early detection improves the outcomes or survival rates of breast cancer, hence screening of asymptomatic, apparently healthy women is very essential, especially when there are risk factors such as the history of breast cancer in immediate relatives. ${ }^{4}$

A number of screening tests are being employed; these include breast examinations, mammography, molecular imaging and genetic screening; ultrasound and magnetic 
resonance imaging, however the three main screening tests are breast examinations, mammography and ultrasound. ${ }^{4}$ The awareness of breast cancer and the importance of screening have increased over the years ${ }^{5}$ however the bane of unaffordability still persists. Poor participation in screening programs has persisted despite the increase in awareness. ${ }^{6}$

Mammography, though presently the method of choice for screening and diagnosis is costly in Nigeria and not widely available in terms of infrastructure and technical/personnel capability. ${ }^{5}$ It also has limited sensitivity in dense breasts. ${ }^{7}$ Ultrasound is widely accessible and affordable and is presently utilized as an adjunct to mammography. It does not utilize ionising radiation, which in itself induces more cancers. ${ }^{7}$

This study compared the use of ultrasound and mammography as breast cancer screening tools in women who attended free breast cancer screening exercise in a centre in Lagos, by characterizing and comparing the prevalent breast parenchyma, features of breast cancer and the independent sensitivity of ultrasound and mammography.

\section{METHODS}

This cross sectional comparative study recruited 300 consenting women based on calculated minimum sample size using Buderer's formula ${ }^{8}$ for sensitivity and specificity,

Sample size based on sensitivity ${ }^{8}$

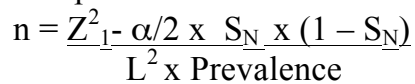

Where $\mathrm{n}=$ required sample size; $\mathrm{S}_{\mathrm{N}}=$ anticipated sensitivity- $80 \%(0.08) ; \mathrm{S}_{\mathrm{P}}=$ anticipated specificity $-78 \%$ $(0.78) ; \alpha=$ size of the critical region $(1-\alpha$ is the confidence level); $Z^{2}{ }_{1-} \alpha / 2=$ standard normal deviate corresponding to the specified size of the critical region 1.68 and $\mathrm{L}=$ absolute precision desired on either side (half-width of the confidence interval) of sensitivity or specificity -0.10 .

A systematic random sampling technique was used to select participants between 30 and 60 years of age, who attended the free breast cancer screening campaign in a tertiary hospital in Lagos State. Clients with symptoms (mastalgia, nipple discharge or lump), previous breast lump excisions or biopsies, history of trauma, who had never breastfed, and pregnant and lactating mothers were excluded from the study.

Two (2) experienced radiographers at the centre were trained on the objectives, technique and rationale of the study for two days for one hour per day. Four (4) expe- rienced radiologists were also trained; two (2) on how to document findings of ultrasound and two (2) on documentation of findings of mammography. This was to reduce observer/examiner bias and variability.

\section{Study Instruments}

The questionnaire self-designed, pre-tested and validated by two renowned experienced radiologists, consisted of 3 sections on socio-demography, reproductive health, and documented findings of parenchymal types and breast cancer features.

\section{Imaging Technique}

Mammography: With strict adherence to standard protocols, the standard medio-lateral oblique and craniocaudal views bilaterally were used to conduct this procedure by the trained radiographers. Findings were reviewed and documented, and additional views taken when required by the trained radiologists.

Ultrasonography: Adhering to the standard protocols ultrasonography was done by the trained radiologists, both breasts and axillae were scanned. The images were reviewed real time on screen; findings were documented. All suspicious (BIRADS 3 and above) lesions for both modalities were sent for histology with findings also documented.

\section{Data Analysis}

The data was analysed using the SPSS for Windows version 18.0 software program. . For ease of comparison, the breast parenchymal density was divided into two broad groups (fatty (BIRADS A and B) and fibroglandular (BIRADS $\mathrm{C}$ and D). The breast density (BIRADS A - D) and total number of detected participants' lesions were assessed for the total patient population, as well as for subpopulations grouped by age (30 39 years, 40 - 49 years, $>50$ years) and hormonal status (premenopausal or postmenopausal).

The lesion detection rates were reported for each modality, both for lesions detected solely with that modality and for lesions detected with a combination of those modalities. Performance characteristics of each screening modality, including sensitivity, specificity, positive and negative predictive values were calculated. Categorical variables were presented in tables. For significant difference, chi square and a $\mathrm{p}$ value of 0.10 were used to reduce the dense sample of 768 to 300 in line with available resource.

\section{Ethical approval}

Ethical approval was obtained from the Health Research and Ethics Committee of the Lagos University Teaching Hospital, and all other research protocols were strictly 
adhered to. Assigned ethical clearance number $\mathrm{ADM} / \mathrm{DCST} / \mathrm{HREC} / 1486$.

\section{RESULTS}

Socio-demographic and Reproductive Health

This predominantly married $261(87.0 \%)$, tertiary educated 285(95.0\%), professional 227(75.7\%), Yoruba $195(65.0 \%)$ respondents, had an age range of 30 to 60 years and a mean age of $41.01 \pm 6.5$ years. Over half $(55.0 \%)$ were between $30-39$ years.

Up to $(112,37.0 \%, 75$, and $25 \%)$ had 2 and 3 children respectively, $165(55 \%)$ were premenopausal, 8 out of 10 participants did not use any form of contraceptive $251(83.7 \%)$. History of alcohol ingestion was by 33 (11\%), and smoking 5 (1.7\%). Only 17(6.7\%) had a family history of breast cancer in a close relative. Participants were predominantly married, tertiary educated, professional with over 55\% between 30 -39years (see Table 1).

Table 1 Socio-demographic distribution

\begin{tabular}{|c|c|c|}
\hline & Frequency $(\mathbf{N}=300)$ & Percentage \\
\hline \multicolumn{3}{|l|}{ Age (Years) } \\
\hline $30-39$ & 139 & 46.3 \\
\hline $40-49$ & 127 & 42.3 \\
\hline$>\mathbf{5 0}$ & 34 & 11.4 \\
\hline Mean age & $41.01+6.5$ & \\
\hline \multicolumn{3}{|l|}{ Marital Status } \\
\hline Single & 26 & 8.7 \\
\hline Married & 261 & 87.0 \\
\hline Others* & 13 & 4.3 \\
\hline \multicolumn{3}{|l|}{ Level of education } \\
\hline Completed secondary & 15 & 5.0 \\
\hline Tertiary & 285 & 95.0 \\
\hline Others ${ }^{* *}$ & 23 & 7.7 \\
\hline \multicolumn{3}{|l|}{ Occupation } \\
\hline Professional & 227 & 75.7 \\
\hline Skilled & 45 & 15.0 \\
\hline Unskilled & 28 & 9.3 \\
\hline $\begin{array}{l}\text { Others } *=\text { divorced, sep } \\
\text { Others } * * *=\text { Traditional }\end{array}$ & ted; Others $* *=E f i k$, & Ijaw, Urobo; \\
\hline
\end{tabular}

\section{Prevalent Breast Parenchyma}

Similar findings of breast parenchyma were noted using ultrasound fatty 237(79\%), fibroglandular 63(21\%)\} and mammography \{fatty (BIRADS A and B) 233 (77.7\%), fibroglandular (BIRADS C and D) 67 $(22.3 \%)\}$ with fatty tissue predominant in all age groups.

Mammography however detected less fatty than fibroglandular tissues in all the age groups. The distribution of parenchyma in the age groups was not statistically significant. Fatty parenchyma (BIRADS A and B). Fibro glandular parenchyma (BIRADS C and D). Fatty parenchyma predominated across all age groups.

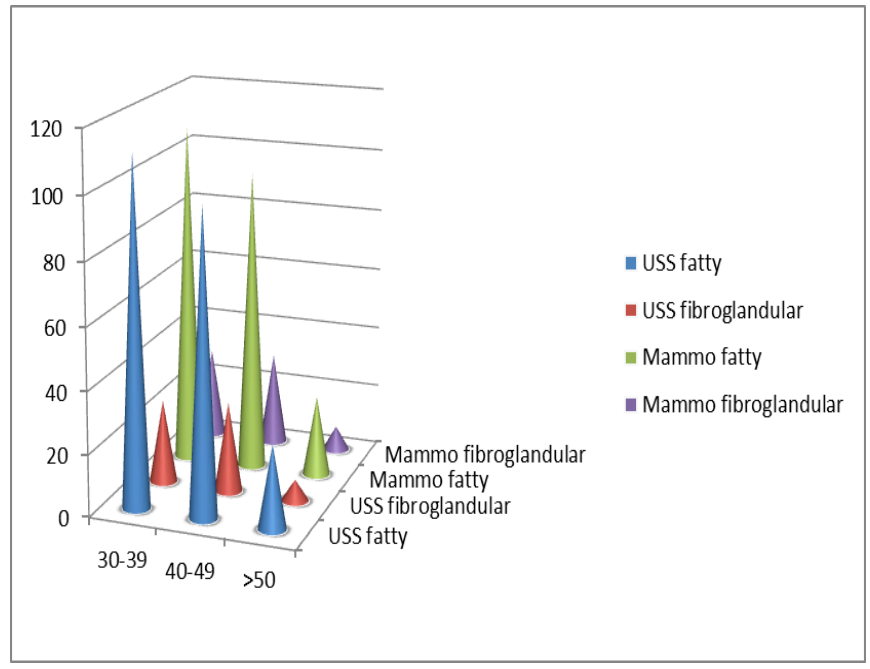

Figure 1 Prevalent breast parenchyma

\section{Features of breast cancer}

Majority, $181(60.3 \%)$ and $174(58.0 \%)$ of the participants had a normal study (BIRADS I) using both ultrasound and mammography respectively. Probable benign lesions (BIRADS III) were seen in $7(2.3 \%)$ and $8(2.7 \%)$ participants using ultrasound and mammography respectively.

Table 2 BIRADS category and features of suspicious lesions seen using ultrasound and mammography

\begin{tabular}{|c|c|c|c|}
\hline & $\begin{array}{l}\text { Ultra- } \\
\text { sound }\end{array}$ & $\begin{array}{l}\text { Mammog- } \\
\text { raphy }\end{array}$ & p-value \\
\hline $\begin{array}{l}\text { BIRADS CATEGO- } \\
\text { RY }\end{array}$ & $\mathbf{N}(\%)$ & $\mathbf{N}(\%)$ & \\
\hline $\mathbf{0}$ & - & $11(8.0)$ & $\begin{array}{l}X^{2}= \\
223.735\end{array}$ \\
\hline I & $181(60.3)$ & $174(58.0)$ & $\mathrm{df}=12$ \\
\hline II & $99(33.0)$ & $86(28.7)$ & $\mathrm{P}=0.000$ \\
\hline III & $7(2.3)$ & $8(2.7)$ & \\
\hline IV & $13(4.3)$ & $8(2.7)$ & \\
\hline \multicolumn{4}{|l|}{$\begin{array}{l}\text { Features of suspicious } \\
\text { lesions }\end{array}$} \\
\hline Mass & $20(100)$ & $11(73.3)$ & 0.185 \\
\hline Spiculations & $10(50)$ & $8(53.3)$ & 21.212 \\
\hline $\begin{array}{l}\text { Thick Incomplete } \\
\text { Halo }\end{array}$ & $3(15)$ & $6(40.0)$ & Fisher \\
\hline Microlobulation & $8(40)$ & $6(40.0)$ & 25.000 \\
\hline $\begin{array}{l}\text { Architectural Distor- } \\
\text { tion }\end{array}$ & $10(50)$ & $10(66.7)$ & 9.642 \\
\hline Microcalcification & $2(10)$ & $4(26.7)$ & Fisher \\
\hline $\begin{array}{l}\text { Axillary lymphade- } \\
\text { nopathy }\end{array}$ & $4(20)$ & $5(33.3)$ & 19.792 \\
\hline \multicolumn{4}{|c|}{$\begin{array}{l}* 0=\text { Inconclusive, I = normal/negative, II = benign, III = probably } \\
\text { benign }(2 \% \text { suspicion of malignancy), IV }-34 \% \text { suspicious of malig- } \\
\text { nancy. Only a few had category III and IV lesions; more were detected } \\
\text { using ultrasound. Commonest features seen were mass, spiculations } \\
\text { and architectural distortion. }\end{array}$} \\
\hline
\end{tabular}

A total of $25(8.3 \%)$ participants had suspicious lesions, out of which $20(6.6 \%)$ were seen by ultrasound and $15(5.0 \%)$ were seen using mammography. 
The difference in distribution of the lesions in ultrasound and mammography were statistically significant (p 0.00) (see Table 2)

Twenty five (8.3\%) participants were suspected of having breast cancer using ultrasound and mammography. The features of breast cancer seen on ultrasound and mammography were mass, spiculation, halo, microlobulation, architectural distortion, calcification and axillary lymphadenopathy. Ultrasound detected a mass in all its detected cases $20(100 \%)$ of cases, more than mammography which detected in $11(73.3 \%)$ of 15 detected cases.

Mammography however detected the other features (spiculations 8(53.3\%), architectural distortion $10(66.7 \%)$, microcalcifications 4(26.7\%), axillary lymphadenopathy $5(33.3 \%)$ in a higher proportion than U1trasonography (spiculations $10(50.0 \%)$, architectural distortion 10(50.0), microcalcifications 2 (10.0\%), axillary lymphadenopathy $4(20.0 \%)$; the difference was statistically significant (p 0.001) in all except for halo 6(40.0\%). Microlobulations (ultrasound 8(40\%), mammography $6(40 \%)$ were seen in equal proportions using the two modalities, this was statistically significant $\mathrm{p}$ 0.001 , Table 2 .

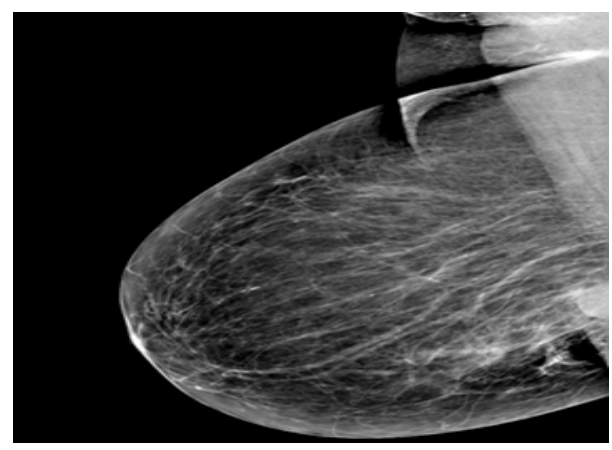

Figure 2 Mediolateral mammogram of the right breast showing a deep seated highly dense breast mass

\section{Sensitivity of Mammography and Ultrasound}

Of the 25 suspected cases of breast cancer, 7 were confirmed malignant histologically. 6 were suspicious on both ultrasound and mammography (BIRADS IV), and 1 on ultrasound alone. The one missed on mammography was seen in an extremely dense (fibroglandular/BIRADS D) breast.

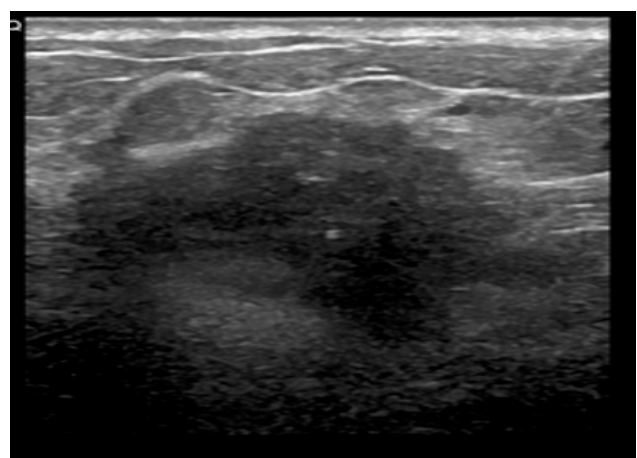

Figure 3 Corresponding ultrasound of the deep seated mass shows a lobulated mass with spiculations.

The diagnostic yield for this study was 23 per 1000 women screened (7/300). Most of the cases with different categories on ultrasound and mammography were benign. Of the mitotic lesions seen, 6 were ductal carcinoma in situ.

Table 3 Histologic findings in suspicious lesions; sensitivity and specificity of the modalities

\begin{tabular}{lccll}
\hline $\begin{array}{l}\text { Number of } \\
\text { participants }\end{array}$ & Ultrasound & Mammography & Histology & Diagnosis \\
\hline 2 & & & & \\
2 & IV & III & Benign & Fibroadenoma \\
4 & IV & IV & Benign & Fibroadenoma \\
3 & II & III & Benign & Fibroadenoma \\
5 & IV & 0 & Benign & Fibroadenoma \\
2 & III & II & Benign & Fibroadenoma \\
6 & III & I & Benign & Fibroadenoma \\
1 & IV & IV & Malignant & DCIS* \\
Sensitivity & IV & 0 & Malignant & IDA* \\
Specificity & 100.0 & 85.7 & & \\
Positive & 22.2 & 55.5 & & \\
predictive & 33.3 & 42.8 & & \\
value & & & & \\
Negative & 100.0 & 90.9 & & \\
predictive & & & & \\
value & & 56.0 & & \\
Accuracy & 84.0 & & & \\
\hline
\end{tabular}

Seven (7) participants had malignant features and commonest was ductal carcinoma in situ (DCIS). Ultrasound had higher sensitivity than mammography.

Ultrasound had high sensitivity in detecting breast cancer $(100 \%)$ but very low specificity $(22 \%)$. Mammography had reduced sensitivity $(85.7 \%)$ compared with ultrasound but was more specific (55.4\%). Positive predictive value was also low in ultrasound (33.3\%) compared with mammography $(42.8 \%)$.

Negative predictive value (100\%) was however higher in ultrasound compared with mammography (90.9\%).

Ultrasound also had a higher accuracy of detecting breast cancer $(84 \%)$ compared with mammography $(56 \%)$. Table 3 
Of the cases confirmed histologically, 6 (85.7\%) were within the 30-39 age group with 4 (57.1\%) having fatty parenchyma. The masses seen on ultrasound measured 5 - 28mm in width in size for both ductal carcinoma in situ and invasive ductal carcinoma. Table 4, Figures 2 and 3.

Table 4 Age group and parenchymal features seen in histologically confirmed cases of breast cancer

\begin{tabular}{llllll}
\hline S/N & $\begin{array}{l}\text { AGE } \\
\text { GROUP } \\
\text { (years) }\end{array}$ & $\begin{array}{l}\text { PARENCHY- } \\
\text { MA } \\
\text { USS (MAMMO } \\
\text { BIRADS) }\end{array}$ & $\begin{array}{l}\text { Ultrasound } \\
\text { size (mm) }\end{array}$ & $\begin{array}{l}\text { Mammo- } \\
\text { graphic } \\
\text { Size } \\
(\mathbf{m m})\end{array}$ & $\begin{array}{l}\text { Histol- } \\
\text { ogy }\end{array}$ \\
\hline $\mathbf{1}$ & $30-39$ & Fatty (A) & $8 \times 11 \times 6$ & $8 \times 10$ & DCIS \\
\hline $\mathbf{2}$ & $30-39$ & Fatty (B) & $28 \times 17 \times 24$ & $20 \times 12$ & DCIS \\
$\mathbf{3}$ & $30-39$ & Fatty (B) & $5 \times 3 \times 3$ & - & DCIS \\
\hline $\mathbf{4}$ & $30-39$ & Fatty (A) & $14 \times 14 \times 14$ & $10 \times 12$ & DCIS \\
$\mathbf{5}$ & $30-39$ & $\begin{array}{l}\text { Fibroglandular } \\
\text { (D) }\end{array}$ & $5 \times 4 \times 4$ & - & DCIS \\
$\mathbf{6}$ & $30-39$ & $\begin{array}{l}\text { Fibroglandular } \\
\text { (C) }\end{array}$ & $6 \times 4 \times 5$ & $8 \times 6$ & DCIS \\
7 & $40-49$ & $\begin{array}{l}\text { Fibroglandular } \\
\text { (C) }\end{array}$ & $28 \times 26 \times 30$ & $21 \times 24$ & IDA \\
\hline
\end{tabular}

Majority were in the $30-39$ age group and were found in fatty breasts, masses seen were comparable in size using both modalities (largest 20mm)

\section{DISCUSSION}

The slightly lower mean age $(41.02 \pm 6.5$ years $)$ than that of Devolli-Disha etal $^{7}$ and Berg etal $^{9}$ (56.56+ 12.60 years and $55.14 \pm 0.19$ years respectively) may probably be due to a wider age range of $30-79$ years and $25-91$ years respectively.

A lower breast density has been noted in African American women compared with Caucasian and Latino women. ${ }^{10}$ This is in consonance with what was seen in this study as the predominant breast parenchyma in the entire study population was fatty (BIRADS A and B) using both ultrasound 237 (79\%) and mammography $233(77.7 \%)$ in almost equal proportion. Predominantly fibro glandular parenchyma was seen in $21-23 \%$ of the study participants in consonant with a Ugandan study with 25\% (BIRADS C and D). ${ }^{11}$

Breast density decreases with increasing age due to a decrease in glandular tissue and its replacement by fat. ${ }^{12}$

This is similar to findings in this study, as the women in the $>50$ year age group had less fibro glandular parenchyma $7(20.6 \%)$ and hence less density than those in the $40-49$ year age group $29(22.8 \%)$.
More benign $106(35.3 \%)$ than malignant lesions $7(2.3 \%)$ were seen in the study, as was noted in other studies conducted. ${ }^{10,11}$ Akinola et al also had multiple benign lesions in the study of spectrum of mammographic findings; however the frequency was not mentioned. $^{12}$

A high percentage $280 \quad(93.3 \%)$ ultrasound and $263(87.0 \%)$ mammogram of this study population had normal and benign findings (BIRADS 1 and 11) (Table 3), and is consistent with Berg et al's study with only mitotic lesions in $1.5 \%$, leaving normal and benign lesions at $98.5 \%$. ${ }^{9}$ Benign lesions detected by ultrasound 99 (33\%) and mammography 89 (29.0\%) in this study is in contradistinction with Devolli-Disha et al's with $52 \%$, their study population were symptomatic women.?

The most common features seen in this study (using both ultrasound and mammography) that raised a suspicion of breast cancer include mass $20(100 \%)$ versus $11(73.3 \%)$, speculation $10(50.0 \%)$ versus 8 $(53.3 \%)$ and architectural distortion $10(50.0 \%)$ versus $10(66.7 \%)$ using ultrasound and mammography respectively. These findings were statistically significant ( $p$ 0.001) in line with studies done. ${ }^{11,12}$ Ultrasound detected a mass in $20(100 \%)$ of the suspicious cases, more than mammography which detected $11(73.3 \%)$.

This is contrary to a study by Berg et al which found more cancers using mammography than ultrasound. ${ }^{9}$ This may be because patients who had a prior history of breast cancer were not excluded from their study. ${ }^{9}$ It is however similar to what was found during the Avonacrin trial by the American College of Radiology which conducted ultrasound screening of asymptomatic women with dense breasts for three consecutive years. ${ }^{13} \mathrm{Ul}-$ trasound detected 4.2 per 1000 , more than were detected at mammography.

Architectural distortion is another important feature of breast cancer that must not be missed or overlooked. A study found out that of the percentage that had architectural distortion using mammography, $5-7 \%$ were malignant. ${ }^{14}$ Architectural distortion was seen in $10(50 \%)$ and $10(66.7 \%)$ of cases in this study using ultrasound and mammography and all the $7(2.3 \%)$ who were confirmed cases of breast cancer had this feature. The difference may be due to the small study population utilized in this study.

Breast cancer has been known to occur more frequently in those with fibro glandular tissue, especially in the Caucasians. ${ }^{10}$ A researcher estimated a four to six fold increased risk of having cancer compared with women 
with less dense tissue. ${ }^{15}$ In this study however, majority $6(85.7 \%)$ of the 7 participants who had breast cancer were identified as having fatty parenchyma using both ultrasound and mammography. This may be because the study is done in an African population who have less dense tissue than their Caucasian or Latino counterparts. ${ }^{10}$

Mammography has inherent limitations with a reported false negative rate of $10-15 \% .{ }^{15}$ Ultrasound on the other hand is highly sensitive with a high false positive rate, which results in a high cost of benign biopsies when compared with mammography. ${ }^{13}$ These findings are similar to what was found in this study.

The sensitivity and specificity of each imaging modality were assessed with ultrasound yielding a high sensitivity $(100 \%)$ and low specificity $(22 \%)$ and mammography having a lower sensitivity than ultrasound $(85 \%)$, but a much higher specificity $(55.5 \%)$.

The ultrasound specificity is similar to what is obtained in older studies in which inadequate detection of smaller cancer and false positive biopsy rates have been documented; ${ }^{14}$ however it is unlike what is now obtained in literature, in which high specificity is recorded. ${ }^{14}$ This may be due to the fact that ultrasound is highly operator dependent and images tissue planes rather than the whole breast. The sensitivity and specificity of mammography in this study were however similar to what was seen in other studies, in which sensitivities ranged between $80-90 \%{ }^{10}$

The accuracy of ultrasound is also higher than that of mammography, as seen in a study in which ultrasound was able to detect 4.2 more cancers than were detected by mammography. ${ }^{16}$ Similar findings were seen in this study as the diagnostic accuracy of ultrasound (84\%) was higher than that of mammography $(56 \%)$.

\section{CONCLUSION}

Ultrasound and mammography were both used as screening tools in this study, however ultrasound was better as a first line of screening due to its high sensitivity especially in dense breasts. Both were useful in denoting the type of breast parenchyma. The type of parenchyma prevalent in this study was fatty, about 20 $25 \%$ had fibro glandular parenchyma.

Majority of the lesions detected on screening were benign with fibro adenomas being the commonest lesion. Ultrasound was able to detect more lesions than mammography especially in women with dense breasts and was able to characterise cystic from solid lesions.
The features of breast cancer were mass, architectural distortion, speculations and micro calcifications. Ultrasound detected more masses than mammography; however mammography was better at detecting micro calcifications, which was one of the first features that suggest an interval cancer.

\section{RECOMMENDATIONS}

The importance of screening cannot be overemphasized. The Federal, State and Local government should develop policies and guidelines that would ensure routine screening of all women for breast cancer. Adequate funds should be made available and manpower strengthened for the implementation of integrated specific vital public health breast cancer programmes.

It is also recommended that annual breast screening should commence from the age of 30years, using ultrasound as a first line screening tool in nulliparous women and parous women or both ultrasound and mammography in order to increase accuracy. Ultrasound can be used as a first line of screening especially in remote /rural areas of the developing world.

\section{REFERENCES}

1. Jedy-Agha E, Curado MP, Ogunbiyi O et al. Cancer incidence in Nigeria: a report from populationbased cancer registries. Cancer Epidemiol. 2012;36(5):e271-8.

2. Adebamowo CA, Hu FB, Cho E et al. Dietary patterns and the risk of breast cancer. Ann Epidemiol 2005; 15 (10): 789-795.

3. Nemesure B, Suh-Yuh W, Ian R, Leske C et al. Risk factors for breast cancer in a black population. The Barbados National cancer study. Int J Cancer 2009; 124 (1): 174-179. doi: 10.1002/ijc.23827

4. World Health Organisation (WHO). Breast cancer: prevention and control.

http://www.who.int/cancer/detection/breastcancer/e n/index1.html. (last accessed 05/06/13)

5. Oche MO, Ayodele SO, Umar AS. Breast Cancer and Mammography: Current Knowledge, Attitudes and Practices of Female Health Workers in a Tertiary Health Institution in Northern Nigeria. Public Health Research, 2012; 2(5):114-119. doi: 10.5923/j.phr.20120205.01.

6. Lawal O, Murphy FJ, Hogg P, Irurhe N, Nightingale J. Mammographic screening programs - a critical comparison to other countries. Radiography 2015;21(4):348-351

7. Devolli-Disha E, Manxhuka-Kerliu I, Ymeri H et al. Comparative accuracy of mammography and ultrasound in women with Breast symptoms accord- 
ing to age and Breast density. J Basic Med. Sci 2009; 9(2): 131-136.

8. Buderer NM. Statistical methodology: I. incorporating the prevalence of disease into the sample size calculation for sensitivity and specificity. Acad Emerg Med. 1996;3(9):895-900.

9. Berg W, Gutierrez L, Nessaiver M et al. Diagnostic accuracy of mammography, clinical examination, US and MRI in preoperative assessment of breast cancer. Radiology 2004; 233(3): 830 - 849.

10. Chen Z, Wu AH, Gauderman WJ. Does mammographic density reflect ethnic differences in breast cancer incidence rates? Am J Epidemiol. 2004; 159(2): 428 - 437. PMID:14718215.

11. Galukande M, Kiguli_Malwadde E. Mammographic breast density patterns among a group of women in Sub Saharan Africa. Afr Health Sci 2012;12:422425

12. Akinola RA, Akinola OI, Jinadu FO. Spectrum of mammographic findings in a tertiary hospital in Nigeria. Sci Res Essay. 2007; 2(12): 502 - 507.
13. Berg WA. Rationale for a trial of screening breast ultrasound: American College of Radiology Imaging Network (ACRIN) 6666 Am J Roentgenol 2003;180:1225-1228.

14. Michell MJ, Al-Attar MA. Detection of subtle mammographic signs of malignancy. www.appliedradiology.mobi/uploadedfiles/Issues/2 003/09/Articles/AR_09_03_Michell.pdf. Accessed Jan 2015

15. Varghese J.S. Mammographic density as an early indicator of breast cancer. In: Benson JR, Gui G, Turtle TM. Early breast cancer, from screening to multidisciplinary management. Third edition. CRC press/Taylor and Francis group, Chennai, 2013: Chapter 2, Page 13-14

16. Devolli-Disha E, Manxhuka-Kerliu I, Ymeric H, KutIIovaca S. Comperative accuracy of mammography and ultrasound in women with Breast symptoms according to age and Breast density. J Basic Med. Sci 2009; 9: 131-136. 